\title{
O Químico na Indústria; perfil e formação a vários níveis
}

O texto que a seguir se apresenta foi elaborado com vista ao lançamento da discussão sobre este tema, realizada em mesa-redonda no 7. Encontro Nacional de Química (Lisboa, 9-14 de Julho de 1984). Participaram na sua elaboração: Dr. José da Costa Reis, CNP, (moderador da mesa-redonda); Doutor Carlos Barral, Departamento de Gestão, UNL; Eng. Vasco Bordado, Quimigal; e Prof. Carlos Nieto Castro, FCL.

A Universidade, tradicionalmente tão orgulhosa da sua independência, necessita, cada vez mais, da Indústria. Esta, por seu turno, que durante anos terá aceitado com algum desdém, uns quantos diplomas mas, quantas vezes, sem reconhecer a sua essência científica, escolhe agora, cada vez mais criteriosamente, os químicos destinados às diversas funções específicas.

Talvez por esta razão os últimos anos tenham registado o aparecimento de várias licenciaturas novas, ou a diversificação das anteriormente existentes, na área da química. Por vezes acontece mesmo haver licenciaturas com designações tão parecidas, que a escolha entre elas constitui um verdadeiro quebra-cabeças, para o candidato à frequência Universitária.

Isto para não falar dos casos em que, pura e simplesmente não há escolha, mas apenas o agarrar de uma vaga, quantas vezes numa área diferente da desejada, mas. como única hipótese viável de curso superior.

Considerações aparte, tomámos como princípio que, se um indivíduo tira um curso de química é porque gosta de química e portanto deseja exercer a sua actividade nesta área.

Parece que desde logo três hipóteses são possíveis:

- seguir uma carreira docente;

- seguir uma carreira de investigação científica;

- seguir uma carreira na indústria.

Nesta mesa-redonda propomos como tema exclusivo do debate o caso do indivíduo que optou por (ou escolheu, ou lhe foi facultada, como se quiser) uma carreira na indústria.

À partida a Indústria oferece ao químico várias actividades possíveis, que a seguir enumeramos, com o objectivo de arrumar ideias, mas sem excluir outras classificações ou aspectos que os presentes desejem apresentar:

ou uma actividade mais ligada à produção - técnicos de produção, de corrosão, de tratamento de águas, de efluentes, chefes de unidades integradas em complexos fabris;

ou uma actividade mais ligada aos projectos industriais tanto de novas unidades ou instalações como de alterações das unidades existentes;

ou uma actividade mais ligada aos laboratórios à caracterização e avaliação de produtos, ao controlo de qualidade, à metrologia, ao desenvolvimento de novos produtos ou alteração dos existentes; ou uma actividade mais ligada à área comercial isto é, uma actividade técnico-comercial, por exemplo de assistência técnica a clientes, de apoio após venda, de rastreio de novos clientes, de auscultação da necessidade de novos produtos, de venda técnica, ou de chefia de produtos, modalidade há muito existente nas empresas multinacionais e que parece começar agora a ser bastante bem aceite entre nós;

ou finalmente, uma actividade mais ligada ao que hoje se designa por investigação e desenvolvimento à qual nos voltaremos a referir dentro de instantes.

Como é evidente a Indústria oferece também carreiras mistas não só com as componentes que acabamos de enunciar mas também com outras, principalmente devido à pequena dimensão de muitas empresas. Um exemplo claro é o da pequena ou média empresa com um único universitário (e é quando o tem) em que, para alem de todas as componentes referidas, se lhe pedem responsabilidades nas áreas comercial, de pessoal, na contabilidade, quando não na gestão financeira.

Mas quando um jovem licenciado acaba o seu curso e procura colocação ele não tem, à partida, em nossa opinião, a noção clara destas grandes linhas de acção e opção. E, mesmo que a tivesse, outros factores, escassez de empregos, esclarecimento involuntária ou propositadamente incorrecto por parte da entidade empregadora, ou também, e é importante referi-lo, indecisão por parte do próprio jovem, ao qual a falta de estágios nas diversas funções e ainda no período escolar, não permite, para além de alguns (diríamos raros) casos de vocação acentuada, analisar correctamente as suas tendências e fazer opçōes sobre o seu próprio futuro.

Mas, para além daquilo a que poderíamos chamar ocupação inicial, o jovem licenciado vai, pouco a pouco, consciencializar-se do que é uma carreira. E é aqui que nos parece haver três grandes linhas possiveis de evolução:

- A generalização;

- A especialização;

- A passagem para a gestão.

Mais uma vez acentuamos: trata-se de uma arrumação de ideias. A assistência terá porventura diferentes pontos de vista a este respeito que serão bem vindos à discussão.

Por generalização designaríamos um tipo de carreira em que o indivíduo vai ocupando sucessivamente, dentro da mesma organização ou em organizações diferentes, com ou sem evolução hierárquica, lugares nas diversas áreas de actividade referidas.

$\mathrm{Na}$ especialização não há, em princípio, mudança de ramo. Vão-se levando sucessivamente mais longe os conhecimentos numa área específica de intervenção, a 
qual tenderá talvez, e precisamente por causa disso, a restringir-se em largura e aumentar em profundidade. Tal como no caso anterior esta evolução pode ser feita com ou sem evolução hierárquica e com ou sem mudança de companhia.

Na passagem para a gestão consideramos o caso em que, após algum tempo de preenchimento de um lugar, o indivíduo é conduzido (ou se conduz) para actividades em que as componentes técnicas tendem a diminuir e outras a aumentar, conduzindo-o a uma situação, de algum modo, propícia à passagem para lugares de gestão.

Até que ponto têm os jovens licenciados consciência (e tentam planear) a carreira que desejam?

Estarão as companhias portuguesas a criar, planear, planificar, organizar, numa palavra, a oferecer aos licenciados nos diversos ramos da química projectos de carreira suficientemente aliciantes?

Se estes aspectos não forem devidamente valorizados corre-se o risco de chegar a um triste resultado: frustração, inoperância, apatia, maus resultados pessoais e, por somatório, colectivos, fracasso, acumulação de decisões erradas, tudo resultando inevitavelmente no aparecimento e avolumar de prejuízos.

É importante recordar que a indústria em geral e a indústria química em particular é um negócio e os negócios não se fazem para acumular prejuízos, mas sim para gerar benefícios. Esta é uma verdade evidente, mas muitas vezes esquecida pelos intervenientes, $a$ todos os níveis, da nossa química industrial.

E, sendo um negócio, e devendo ser um negócio, é oportuno pensar quem the deve assumir a direcção:
- Os químicos, após terem aprendido as realidades da indústria?

- Os habilitados com cursos de gestão de empresas?

- Os economistas? Os advogados? Quem?

Eis aqui outra pista que talvez interesse discutir.

Como negócio que é, a indústria para sobreviver com êxito, exige uma evolução constante e é por isso que se tem vindo a assistir à crescente importância dada ao complexo conjunto de actividades que se designam habitualmente por investigação e desenvolvimento.

À primeira vista a grande diferença que parece haver entre a investigação exclusivamente universitária e a investigação efectuada pelos, ou para os, organismos ditos de I\&D das empresas, consiste em que, nesta os conhecimentos não se divulgam à medida que se adquirem. Desenvolvem-se e, depois, eventualmente, patenteiam-se.

Só então se publicam e, ainda assim, por forma a dar a notícia sem dar necessariamente a informação.

A escassez de patentes registadas pela indústria química nacional, bem reveladora do seu grau de desenvolvimento, talvez mereça também, alguns comentários da vossa parte.

Para finalizar proporíamos à vossa atenção $a$ oportunidade de conjugação de esforços entre a universidade $e$ a indústria, por forma a utilizar realmente os recursos já disponíveis, tanto humanos, como em equipamento e materiais, e a justificar outros que, apesar das magras verbas dedicadas entre nós à investigação e ao desenvolvimento, possam ser suportadas pelo conjunto nacional.

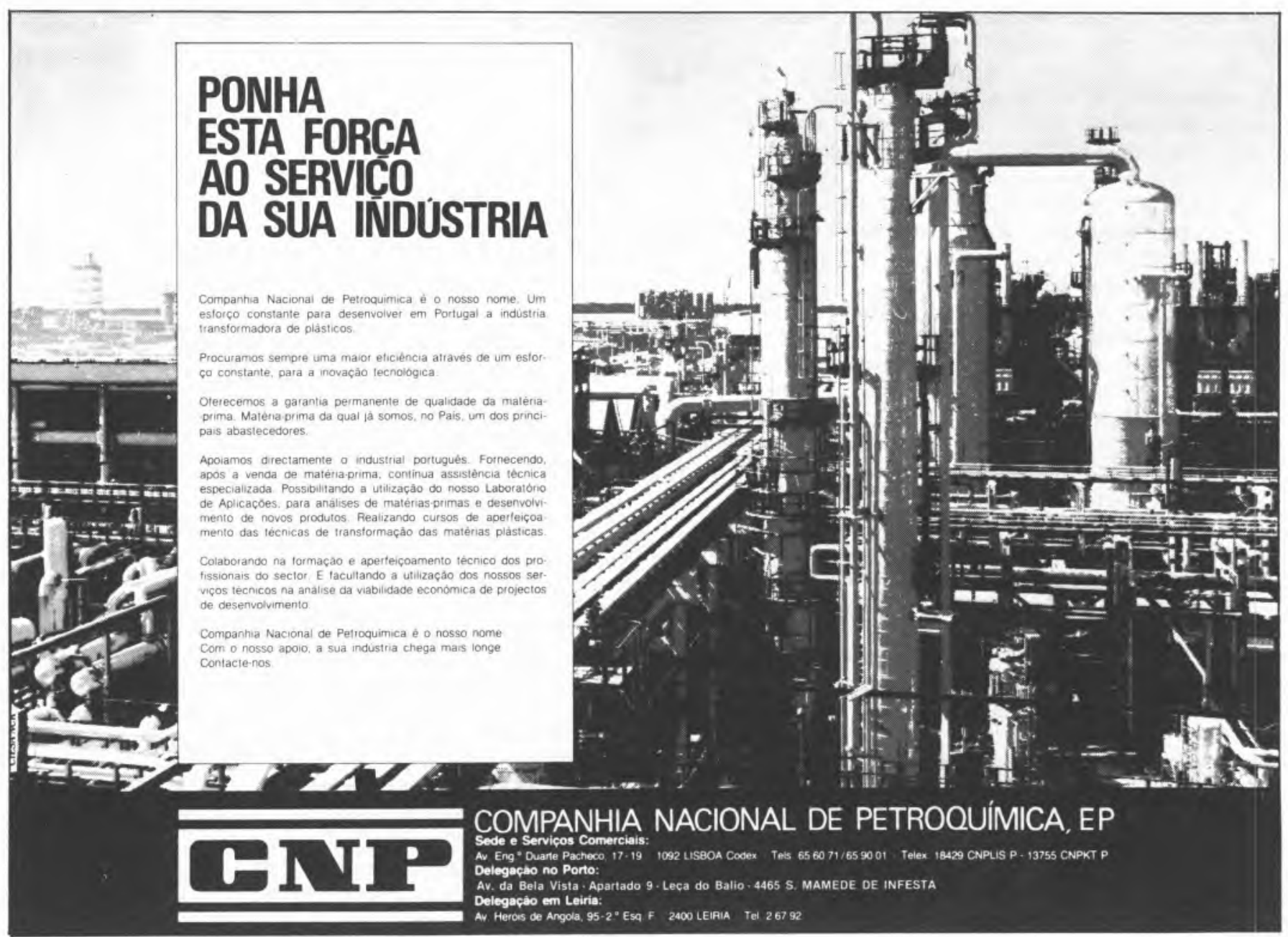

